\title{
InfLuence of Canal Geometry and DYNAMICS ON CONTROLLABILITY
}

\author{
By T. S. Strelkoff, ${ }^{1}$ Member, ASCE, J. L. Deltour, ${ }^{2}$ C. M. Burt, ${ }^{3}$ \\ A. J. Clemmens, ${ }^{4}$ Member, ASCE, and J. P. Baume ${ }^{5}$
}

\begin{abstract}
This paper presents the results of the Task Committee on Canal Automation Algorithms with regard to the influence of canal properties on the controllability of irrigation canals. While the control provided by individual algorithms was not evaluated, studies were performed to illustrate inherent hydraulic limitations - the inability of canal pools to recover rapidly from disturbances or flow perturbations. Studies were performed in nondimensional form to develop a better understanding of how pool properties influence pool response. Three such studies were performed. First, nondimensional backwater curves were developed for a range of canal conditions. The second study involved the propagation of waves initiated at the upstream end of a canal pool, as this is influenced by downstream boundary conditions. Finally, the response of pools to downstream withdrawals was examined in terms of their sluggish recovery even when the correct flow change is applied upstream. These results will help in understanding how canal properties influence the ability of operators to effectively control a canal either manually or automatically, and should influence future design practices.
\end{abstract}

\section{INTRODUCTION}

Over the past several decades, much attention has been given to methods for (1) Controlling canal downstream water levels or volume with feedback control; (2) routing flow changes through canals with open-loop or feedforward control; and (3) utilizing local structures for controlling either water levels or flows (see Malaterre et al. 1998; Rogers and Goussard 1998; Bautista et al. 1997; Burt and Plusquellec 1990; and "Planning" 1987 for further details). However, the success of any of these schemes is largely dependent upon the properties and characteristics of the canal itself, independent of the control method being used. This was one conclusion of the ASCE Task Committee on Canal Control Algorithms.

There is little in the literature examining the limitations that canal properties place on controllability. Rogier et al. (in "Planning" 1987) describe the change in pool volume required to move from one steady state condition to another. The pool cross-sectional shape, slope, length, hydraulic resistance, and water levels in relation to normal depth all influence this volume change. For application of Dynamic Regulation on the Canal de Provence, these relationships were determined for each canal pool. No analysis of the transient nature of the phenomenon was attempted. The task committee formed a group to look at the transient phenomenon in a generic way, applicable to different systems.

First, a nondimensional representation of canal properties was developed to reduce the number of parameters required to display the results and to develop an understanding of the relationships that actually influence canal response (Strelkoff et al. 1995a). Next, nondimensional steady state backwater

\footnotetext{
${ }^{1}$ Res. Hydr. Engr., U.S. Water Conservation Lab., USDA/ARS, 4331 E. Broadway, Phoenix, AZ 85040; and Res. Prof., Univ. of Arizona, Tucson, AZ 85721.

${ }^{2}$ Water Control Engr., Société du Canal de Provence (SCP - member co. of GERSAR), BP 100, 13603 Aix-en-Provence, Cedex 1, France.

${ }^{3}$ Prof. and Dir., Irrig. Training and Res. Ctr., California Polytechnic State Univ., San Luis Obispo, CA 93407.

${ }^{4}$ Supervisory Res. Hydr. Engr., U.S. Water Conservation Lab, USDA ARS, 4331 E. Broadway, Phoenix, AZ.

${ }^{5}$ Hydr. Engr., Cemagref, 361 Rue J-F Breton, BP 5095, 34033 Montpellier, Cedex 1, France.
}

curves were examined for a range of conditions. Strelkoff et al. (1995b) then examined the propagation of waves through a canal pool and the influence of the pool properties, especially the downstream boundary conditions, on the response of the water levels to flow changes. Burt et al. (1995) examined the influence of canal pool properties on the speed with which a canal could respond to unanticipated downstream withdrawals. This last study essentially determines the limitations on the ability of feedback control systems to achieve downstream control. From them, one can quantify the amount of flow change that can be accommodated by feedback alone. Greater flow changes require advance knowledge and feedforward routing, i.e., control measures applied in anticipation of an expected event in order, for example, to avoid unacceptable changes in downstream water levels. These studies are independent of gate hydraulics and control-algorithm characteristics.

Because of the important role played by pool properties in canal controllability, the task committee formulated a set of test cases, so that different algorithms could be tested under the same conditions (Clemmens et al. 1998). These test cases were intended to help algorithm developers judge their results on a broader basis than site-specific, perhaps easily controllable, conditions alone. The purpose of this paper is to present the findings of these task committee studies as an aid to understanding how various canal properties influence selection of control methods and determination of their limitations.

\section{STEADY STATE CHARACTERISTIC CURVES FOR A POOL}

Fig. 1, drawn from Deltour (1992), graphically displays ultimate pool-volume responses to control measures. These curves characterize the full range of steady states possible in a pool of given dimensions. Developed from multiple computer simulations of backwater curves in a single, specific pool, they show how the volume in transit within the pool changes with flow rate and depth at the downstream end of the pool. The dashed curves are lines of constant depth at the upstream end; the solid curves are contours of downstream depth. The heavy solid curve on the right represents normal depth; upstream and downstream depths are identical. If depths between normal and critical were included, they would occupy a narrow region to the right of the normal-depth curve (Deltour 1992).

As discharge rates in the canal are changed, depths and pool volumes change in response. Both responses are of interest. The depths, of course, are of interest in their influence on 


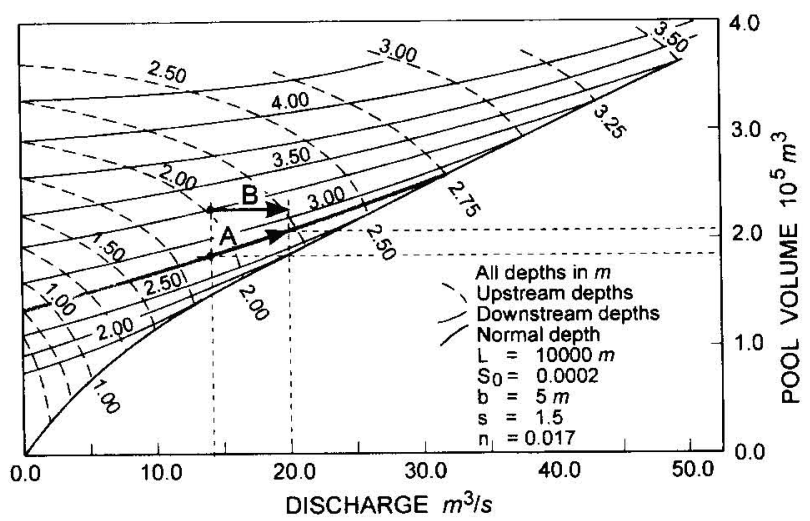

FIG. 1. Steady State Characteriatic Curves for Specified Pool: Stored Volume as Function of Flow Rate and Water Level (Deltour 1992; Burt et al. 1995)

offtake flows and on the safety of canal operation. The volume changes and the accompanying discharges relate to the time necessary to effect the change in storage required to complete the process of adjustment to new flow rates. The diagram provides valuable insight into the controllability of the given pool.

In terms of initial and final steady states, when wave action has died down and a new equilibrium state has evolved, Fig. 1 can be used to chart the changes resulting from different control strategies. For example, with the control point at the downstream end of the pool, and the water depth there held, say, to $2.75 \mathrm{~m}$, all possible states of checked-up, steady flow in the canal pool are represented by the heavy gray curve in the figure. Then, if the flow were to change, say, from 14 to $20 \mathrm{~m}^{2} / \mathrm{s}$, as shown by the heavy arrow A, the upstream depth will change from 1.89 to $2.20 \mathrm{~m}$; furthermore, a volume of $21,000 \mathrm{~m}^{3}$ must be added to the pool before a new steady state can be reached.

Fig. 1 can also be used to examine constant-volume control based on a downstream control point. With inflow and outflow rates always identical, the volume in the pool remains constant. Thus, for example, if the discharge was $14 \mathrm{~m}^{3} / \mathrm{s}$ initially, with a downstream depth of $3.25 \mathrm{~m}$ (and $2.02 \mathrm{~m}$ upstream), and then we simultaneously increase the flow at both ends of the reach to $20 \mathrm{~m}^{3} / \mathrm{s}$, the new downstream water level must be $3.10 \mathrm{~m}$, and the upstream depth, $2.28 \mathrm{~m}$. This change is shown by the heavy arrow B in Fig. 1. With no changes in pool volume needed to effect the change in conditions, this response would be speedier than for the case represented by $A$.

This approach was also used in Deltour (1992) to estimate the minimum depth reached in unsteady-flow simulations, before correction by the controller increasing the volume in the pool. The adequacy of this estimate was also tested in a field study (Sanfilippo 1994) on the MSIDD WM lateral canal, with favorable results.

The curves of Fig. 1 were prepared for a specific canal pool. They cannot be used to predict response behavior in other pools, with different geometries or flow rates. To prepare or even present such curves in a general way, for the practical range of pool lengths, sizes, slopes, roughnesses, flow rates, etc., is practically impossible. Furthermore, these curves show only possible steady states and do not formally consider the transient depth changes. To include time variation in such a general study would be still less feasible. However, if such problems are viewed in dimensionless terms, there can be a considerable reduction in computational and presentational effort. We turn next to such dimensionless analyses.

\section{REDUCTION OF SAINT VENANT EQUATIONS TO DIMENSIONLESS FORM}

The rationale for viewing a problem - its governing equations, initial and boundary conditions, and solutions-in di- mensionless form is that the same information can be conveyed with fewer variables, and hence in fewer graphs, charts, and tables. As a result, the general behavior of a system can be more readily discerned. Dimensionless variables are simply the usual variables, with dimensions of length, time, etc., divided by appropriate constant reference variables having the same dimensions as the original variables. There are many possible choices of reference variables, each having its own advantages and disadvantages. Following Strelkoff et al. (1995a), we base the system of reference variables on normal depth at the design discharge of a pool. This limits the applicability of the results to sloping canals.

The equations of Saint Venant in dimensionless, momentum conservation form and with Manning roughness can be written (as in Strelkoff and Clemmens 1998)

$$
\begin{array}{r}
\frac{\partial Q^{*}}{\partial x^{*}}+\frac{\partial A^{*}}{\partial t^{*}}+q_{o}^{*}=0 \\
\mathrm{~F}_{N}^{2} d_{N}^{*}\left[\frac{\partial Q^{*}}{\partial t}+\frac{\partial}{\partial x^{*}}\left(\frac{Q^{*^{2}}}{A^{*}}\right)+u_{o}^{*} q_{o}^{*}\right] \\
+A^{*}\left(\frac{\partial h^{*}}{\partial x^{*}}+R_{N}^{* 43} \frac{Q^{*^{2} n^{* 2}}}{A^{*^{2}} R^{* / 3}}\right)=0
\end{array}
$$

where $x^{*}=$ dimensionless distance along the channel, $x / X_{R} ; t^{*}$ $=$ dimensionless time, $t / t_{R} ; Q^{*}=$ dimensionless discharge, $Q /$ $Q_{R} ; A^{*}=$ dimensionless cross-sectional area, $A / Y_{R}^{2} ; q_{o}^{*}=$ dimensionless distributed lateral outflow per unit length of channel, $q_{o} X_{R} / Q_{R} ; \mathrm{F}_{N}=$ Froude number of given design flow $Q_{N}$ at normal depth $y_{N} ; d_{N}^{*}=$ dimensionless hydraulic depth under design normal flow conditions [see (8)]; $u_{o}^{*}=$ dimensionless longitudinal component of velocity of lateral outflow, $u_{o} / V_{R}$; $h^{*}=$ dimensionless water-surface elevation, $h / Y_{R} ; R_{N}^{*}=$ dimensionless hydraulic radius under design normal flow $R_{N} / y_{N}$ [see (9)]; $n^{*}=$ relative Manning coefficient, $n / n_{R} ;$ and $R^{*}=$ dimensionless hydraulic radius, $R / Y_{R}$. The reference variables, subscripted $R$ above, are based on various physical characteristics of the flow at normal depth $y_{N}$ and the design canal discharge $Q_{N}$, in a reference section, say, at the upstream end of the canal with the bottom slope $S_{0_{R}}$ and Manning roughness $n_{R}$. The reference depth $Y_{R}$ is then set to $y_{N}$. With an aspect ratio $a$ of the canal defined as the ratio of average breadth $\bar{B}_{N}$ to depth under these normal conditions, i.e., as the dimensionless normal area $A_{N}^{*}$,

$$
a=\frac{\widetilde{B}_{N}}{y_{N}}=\frac{A_{N} / y_{N}}{Y_{R}}=A_{N}^{*}
$$

The reference discharge is defined as the ratio of normal discharge to aspect ratio,

$$
Q_{R}=\frac{Q_{N}}{a}
$$

This definition of reference discharge ensures that dimensionless velocities, rather than discharge, approach unity under normal conditions.

The remainder of the reference variables follow from the definitions

$$
\frac{X_{R} Y_{R}^{2}}{T_{R} Q_{R}}=1 ; \quad X_{R}=\frac{Y_{R}}{S_{0_{R}}}
$$

and

$$
V_{R}=\frac{Q_{R}}{Y_{R}^{2}}
$$

It follows, too, that the characteristic reference velocity is the normal velocity, $V_{R}=Q_{N} / A_{N}$, and thus, that the dimensionless 
velocity approaches unity as normal depth is approached. In an alternate approach, $Q_{R}$ could be set equal to $Q_{N}$ so that $Q_{N}^{*}=1$ (under design normal conditions); but then $V_{N}^{*}$ would not, in general, equal unity.

\section{APPLICATION OF DIMENSIONLESS EQUATIONS}

A generalized study of canal behavior can be performed directly in dimensionless mode, with the equations, initial and boundary conditions, and solutions all in dimensionless form. The principal independent parameter in the governing equations (1 and 2) is the Froude number $F_{N}$ of normal depth at the design flow; $d_{N}^{*}$ and $R_{N}^{*}$ are shape parameters for the canal cross section, the first influencing dynamic wave speed, and the second, flow resistance. Deviations of Manning roughness from that in the reference section is given by $n^{*}$, and bottom slopes varying with respect to the slope in the reference section by $S_{0}^{*}$. In addition to these parameters, transient solutions are governed by inflows and outflows to and from the system, gate movements, and the initial flow profile. All of these can be expressed in nondimensional form.

Canal shape, for the symmetrical trapezoidal sections studied, is specified by $b^{*}$, base width relative to normal depth, and side slopes $s$. With a dimensionless normal depth of unity, the shape factors $A_{N}^{*}, R_{N}^{*}$, and $d_{N}^{*}$ follow. Indeed, the dimensionless cross-sectional normal flow area and aspect ratio are

$$
A_{N}^{*}=a=\frac{A_{N}}{y_{N}^{2}}=b^{*}+s
$$

the dimensionless normal hydraulic depth,

$$
d_{N}^{*}=\frac{d_{N}}{y_{N}}=\frac{A_{N}}{B_{N}}=\frac{b^{*}+s}{b^{*}+2 s}
$$

and the dimensionless normal hydraulic radius,

$$
R_{N}^{*}=\frac{R_{N}}{y_{N}}=\frac{b^{*}+s}{b^{*}+2 \sqrt{1+s^{2}}}
$$

Thus, all transverse dimensions of the flow are expressed as multiples of normal depth; all longitudinal canal dimensions would be input as multiples of $X_{R}$. Pool length, then, would be specified as $L^{*}$. In a uniform pool, $n^{*}$ and $S_{0}^{*}$ would both be unity. Dimensionless design inflow $Q_{N}^{*}$ would be $a$; its Froude number at normal depth $F_{N}$ must be specified. Any other dimensionless discharges would also be given in reference to $Q_{R}$. Gate openings and amount of checkup would be specified relative to normal depth, and gate-schedule times would be understood relative to $T_{R}$ [see $(5 a)$ ]. Dimensionless offtake outflow velocities (longitudinal components), $u_{0}^{*}$, would be input as a fraction of characteristic, normal velocity (velocity at normal depth for the design inflow computed for the channel geometry and roughness at the reference section of the reach). These typically, are assumed to be zero.

Interpretation of general dimensionless results - i.e., in reference to the real, dimensioned world-is facilitated through the concept of the hypothetical dimensioned channel. Specification of some normal-flow depth, Manning roughness, and normal Froude number allows all dimensionless results to be translated into real, dimensioned terms (Strelkoff and Clemmens 1998).

For the steady state backwater-curve study following, a simple dimensionless model of nonuniform flow was employed. For the unsteady-flow analyses described herein, a custombuilt simulation model was utilized, (a) because standard commercial models do not accommodate the form of (1) and (2); (b) as a matter of convenience for running large groups of simulations in a generalized study; and (c) to allow nonstandard conditions to be readily included in the analysis.
The simulation model, recast as a computer subroutine for the generalized studies, is based on a network of continuous characteristic curves stemming from the characteristic form of the Saint Venant equations (Strelkoff and Falvey 1993). The characteristic form is closest to the theoretical solution of the Saint Venant equations, and it is thought that some aspects of the solution might become apparent only with the characteristics methodology. For example, gradual bore formation (Strelkoff 1992) could be missed altogether with other solution techniques.

This subroutine would be called repeatedly by a main program, which systematically changes the dimensionless canalpool geometry and dynamics in a predetermined pattern. At the conclusion of each simulation, pertinent input and output variables (geometry, initial Froude number, delay times) are automatically entered into a text file, one line per simulation. An auxiliary program would then read this text file, extract the desired data, and plot it. Additional simulations were performed with an implicit finite-difference model for corroboration.

\section{DIMENSIONLESS BACKWATER CURVES}

Dimensionless steady state nonuniform flows exhibit a particularly simple form. In Fig. 2, steady-flow profiles of all checked-up canal pools are described by some portion of the single generalized backwater curve shown. In this case, the downstream limit is a checked-up depth equal to 1.5 times normal depth; variation of normal Froude number over a customary range $\left(0.1<F_{N}<0.7\right)$ and variation of channel cross section and side slopes over their customary ranges $\left(0.5<b^{*}\right.$ $<3 ; 1<s<2$ ) have little effect.

\section{PROPAGATION OF UPSTREAM CONTROL MEASURES ALONG A CANAL POOL}

In order to provide the required amount of water at deliverycanal turnouts in a timely manner, some control measures must be applied upstream from the turnouts as demands change. Whether automatically or manually, pumps must be turned on and off, and canal gates need to be raised or lowered. Determination of the appropriate control measures is complicated by the fact that the response of the canal at the turnouts is not instantaneous. A substantial time delay typically exists between the implementation of a control measure at the upstream end of a canal pool and its arrival at a downstream point (Strelkoff et al. 1995b).

Furthermore, the wave profile slumps as it propagates, so that different portions of the wave arrive at different times. The delay between the first harbinger of a sudden upstream
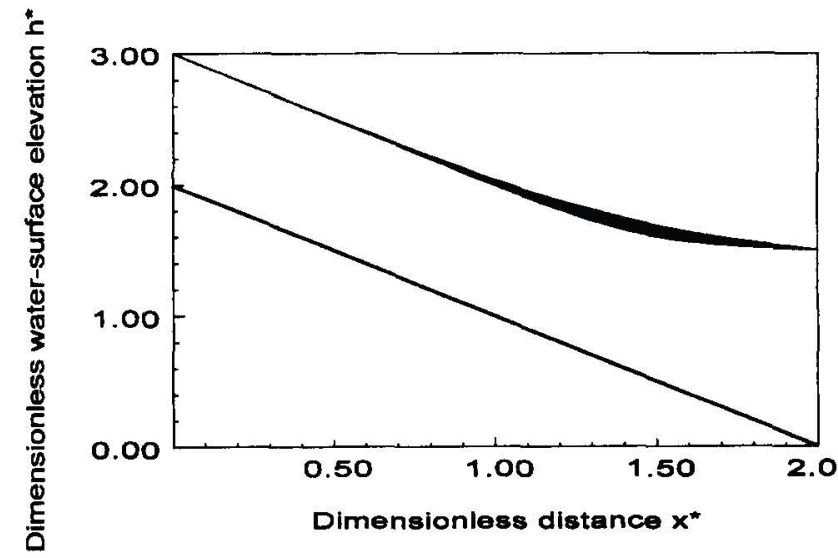

FIG. 2. Dimensionless Steady State Backwater Curves: $0.1 \leq$ $F_{N} \leq 0.7 ; 0.5 \leq b^{*} \leq 3 ; 1 \leq s \leq 2$. Dimensionless Downstream Depth $=1.5$ (Strelkoff et al. 1995a) 
change and the substantial bulk of the wave increases with distance from the upstream end. If the pool were a prism of indefinite length, the wave profiles would eventually assume the fixed form of the well-known monoclinal rising wave (Henderson 1966, p. 372) as in Fig. 3, and all portions would propagate at the same, kinematic-shock, speed

$$
c=\frac{Q_{2}-Q_{1}}{A_{2}-A_{1}}
$$

where the subscript 2 refers to the increased depth and discharge upstream; and 1 refers to the initial, smaller values. But for a significant length of time, the form of the wave initiated upstream as a step increase would be gradually evolving, leading to the observed delays in arrival between the various wave components. Furthermore, nonprismatic canal flows preclude the evolution to a profile of fixed shape, and a case-specific numerical solution of the Saint Venant governing equations becomes necessary in order to predict the time delays.

Fig. 4 shows the evolution of discharge hydrographs (shown relative to initial design flow, $Q_{N}$, rather than as $Q^{*}$ ) in three canal pools, similar but for the downstream structure. In the figure, (a) corresponds to a normal-depth stage discharge relation; (b) to a long-crested weir (duck bill with a length about 21 times the initial normal depth, $y_{N}$ ) of such height that the water depth upstream from the weir equals $y_{N}$ while the head on it is about $0.1 y_{N}$, and (c), to a reservoir, held to an elevation of $y_{N}$ above downstream channel invert. Thus, in every case, the initial dimensionless downstream depth in the pool is $Y_{D}^{*}$ $=1.0$. In fact, the initial flow is uniform, at unit (dimensionless) depth. Dimensionless width $b^{*}=2$; side slopes $s=0$; length $L^{*}=1 ; S_{0}^{*}=1$; and $n^{*}=1$. The initial Froude number in each case is $\mathrm{F}_{N}=0.3 ; d_{N}^{*}=1$; and $R_{N}^{*}=0.5$. The upstream step increase in discharge in each case is $10 \%$ of the initial flow.

Thus, for each case, the pool cross section is rectangular, and for the sake of definiteness, width $b=2 \mathrm{~m}$; normal depth $y_{N}=1 \mathrm{~m}$; initial discharge $Q_{N}=1.9 \mathrm{~m}^{2} / \mathrm{s}$; length $L=2300 \mathrm{~m}$;

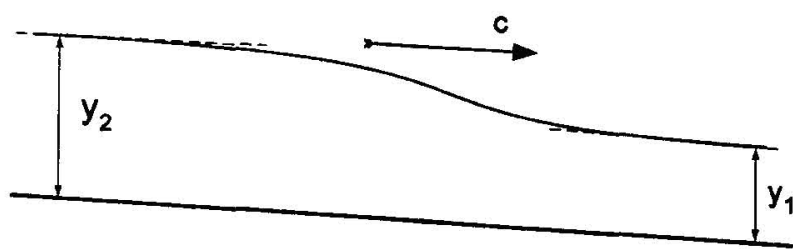

FIG. 3. Typical Profile of Monoclinal Rising Wave: Long Wave Connecting Two Unlform Depths, $y_{1}$ and $y_{2}$, Moving with Kinematic Shock Speed $c$

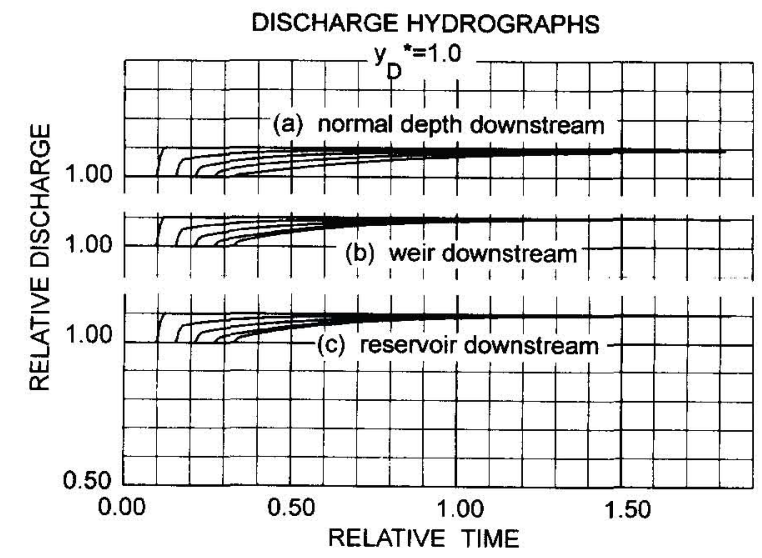

FIG. 4. Discharge Hydrographs in Canal Pool: at Upstream End, 1/4, 1/2, 3/4, and Full-Length Points; Step Increase in Discharge at Upstream End, and Initlal Downstream Depth at Normal (Strelkoff et al. 1995b) bottom slope $S_{0}=0.00044$; and Manning $n=0.014$. Other dimensions are of course possible, and still yield the same dimensionless parameters as the given example. In the example case, the time reference value $T_{R}=41 \mathrm{~min}$.

Hydrographs are shown at the $0,1 / 4,1 / 2,3 / 4$, and fulllength points. At once evident is that the toe of the wave arrives at the same time in all cases. The bulk of the wave, on the other hand, when the downstream boundary condition is a normal-depth stage-discharge relation, arrives substantially delayed, as compared to the other downstream boundary forms. The long weir and reservoir give essentially the same results, which is not surprising since the intent of the long crest is to fix the water-surface elevation independent of the discharge.

Fig. 5 shows similar tendencies for the same pool, but with a checked-up initial flow, provided in (a) by a submerged radial gate; in (b) by a normal-depth stage discharge relation with increased roughness downstream from the nominal end of the pool; and in (c) by the long weir. In each case, the water level was checked up, initially, to a depth about $1.5 y_{N}$.

Again, the leading component of the disturbance arrives at the same time in each case. The bulk of the wave, with nearly the full increase, however, arrives latest with the gate, just a little sooner with the normal-depth stage-discharge relation, and much sooner with the constant downstream depth (longcrested weir).

A program of variation of pool and flow properties was initiated with the three downstream boundary conditions: submerged gate, long-crested weir, and reservoir. Simulations were performed by the characteristics-based model in the first two cases, and with the SIC implicit finite-difference model in the third case for comparison ("SIC" 1992). In this initial study, cross sections were limited to rectangular, with a width two times the initial normal depth, a range of dimensionless pool lengths from 0.3 to 2.0 , checked-up depths equal to 1.0 and 1.25 times normal depth, and Froude numbers of the initial flow equal to $0.1,0.3$, and 0.5 . The step increase in discharge was held to $10 \%$ of the initial flow. Relative times of arrival of $10 \%$ and $85 \%$ of the original upstream step increase are shown in Fig. 6 and 7.

These curves represent the first steps in the development of more extensive curves, covering a wider range of conditions, which could be used at the initial stage of a project to estimate the delays required to bring conditions at the downstream end of a pool in line with upstream changes; i.e., to be able effectively to use the modified discharge at the downstream end of the pool. The more general curves should show the effect of larger increases in discharge, nonzero side slopes, and other relative canal widths. As noted earlier in connection with the sample hydrographs, the delay in arrival of the initial stages

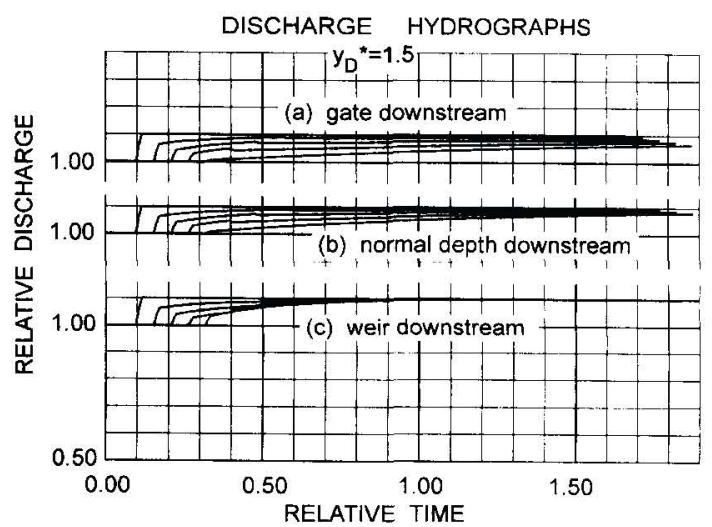

FIG. 5. Discharge Hydrographs in Canal Pool: at Upstream End, 1/4, 1/2, 3/4, and Full-Length Points; Step Increase in Discharge at Upstream End, and Initial Downstream Depth at 1.5 Times Normal (Strelkoff et al. 1995b) 


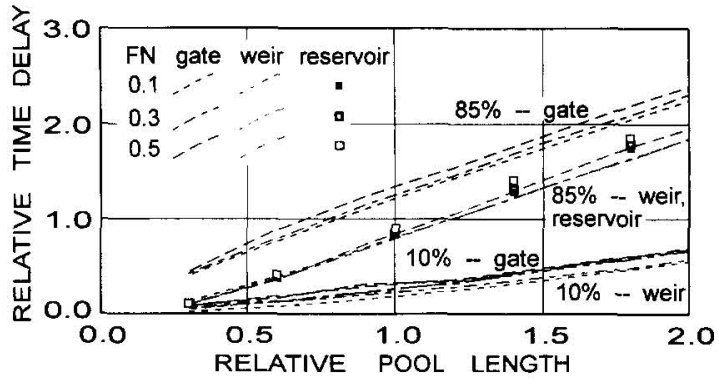

FIG. 6. Delay of Wave Components (Depths): $s=0.0 ; b^{*}=2.00$; $y_{D}^{*}=1.0 ; F_{N}=0.1,0.3,0.5$ (Strelkoff et al. 1995b)

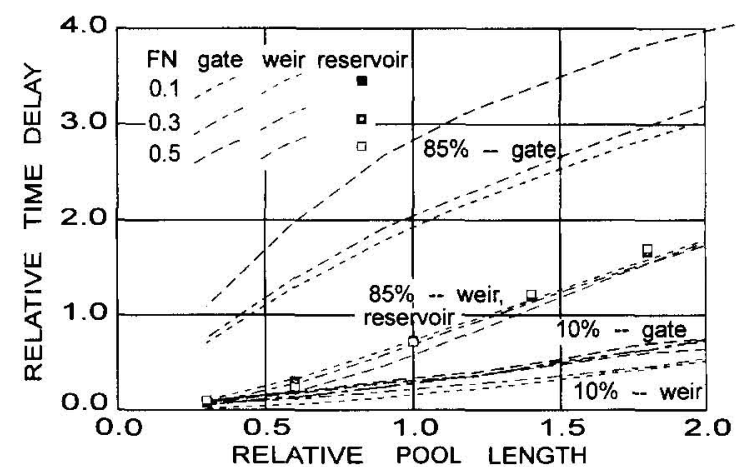

FIG. 7. Delay of Wave Components (Depths): $s=0.0 ; b^{*}=2.00$; $y_{D}^{*}=1.25 ; F_{N}=0.1,0.3,0.5$ (Strelkoff ot al. 1995b)

of the release wave (the $10 \%$ curves), is somewhat dependent on initial Froude number, but little dependent on the degree of check-up or the kind of control structure downstream.

The $85 \%$ delay time varies significantly with checked depth, somewhat less so with Froude number, and is greatly dependent on the nature of the downstream boundary. With the longcrested weir or reservoir downstream, the delay of this component is decreased with an increase in checked-up depth. With the submerged gate, the larger the checked-up depth, the greater the delay. With the gate, increasing Froude numbers result in increased delay; with the long-crested weir, the opposite trend is noted, except with $y_{D}^{*}=1$. At a dimensionless pool length of unity, the global delay is reduced by $30 \%$ if the downstream checked depth is close to normal depth, and 60 $75 \%$ if the downstream checked depth is close to $1.25 y_{N}$. The delay increases because, with increasing checkup, the head loss introduced by the gate increases the variation in level as the wave arrives.

This confirms one of the advantages-reduced delay times - of introducing long-crested check structures (duck-bill weirs) to control the level on canals operating under upstream control (advance scheduling). The time lag introduced by the canal pools is seen to be an important constraint with this type of operation.

\section{RESPONSE OF CANALS TO DOWNSTREAM WITHDRAWALS AND SIMULTANEOUS UPSTREAM REPLACEMENTS}

Even if a controller were capable of inducing immediate and exact replacement of offtake withdrawals upstream from the point of withdrawal, the canal water depth at the offtake still decreases until after the replacements arrive. Then, very gradually, the depth returns to its original level (Burt et al. 1995).

The phenomena are controlled by gravity, resistance, pressure, and inertial forces, the proportions varying with the specific circumstances: reach length, slope, roughness, cross section, initial discharge, downstream conditions, including the degree of check-up, and withdrawal rate. A program of dimensionless unsteady-flow simulations with this simultaneousreplacement scenario quantified the influence of pool geometry and dynamics on maximum, unsteady drawdown. Only partially realized, the intent was to generate a pattern of solutions blanketing the practical range of interest.

In the specified scenario, given fractions $R_{Q}$ of the initial flow rate are withdrawn suddenly and for an indefinite period from an offtake just upstream from the downstream gate (see Fig. 8). Simultaneously the same fraction is added upstream; it is assumed that the upstream gate is somehow controlled to produce this increase. The downstream gate remains at its original setting, which yielded the initial checked-up depth at the downstream end of the pool. Downstream from the downstream gate, an indefinite length of additional canal of the same cross section, slope, and roughness as the given pool is assumed. As a result, the depth on the downstream side remains at normal for whatever discharge is passed. The offtake discharge remains constant after the augmentation. However, in contrast to the preceding constant-volume example (arrow B, Fig. 1) with given gate discharge, now the discharge through the downstream gate varies in accord with variations in depth and discharge coefficient. Gate width is assumed equal to the base width of the canal trapezoidal cross section, resulting in a small decrease in water surface elevation as the flow enters the control structure.

Typical discharge (again relative to normal discharge, $Q_{N}$ ) and depth hydrographs are shown in Fig. 8 for withdrawal fraction $R_{Q}=0.6$, relative pool length $L^{*}=1.6$, relative checkup $y_{D}^{*}=1.3$, and initial normal Froude number, $F_{N}=0.2$. The relative base width in the canal, $b^{*}=2$; side slopes, $s=1.5$; the gate opening relative to normal depth, $D_{G}^{*}$, needed to achieve the given check-up, $D_{E}^{*}=0.7$. The numbers $1-6$ rep-
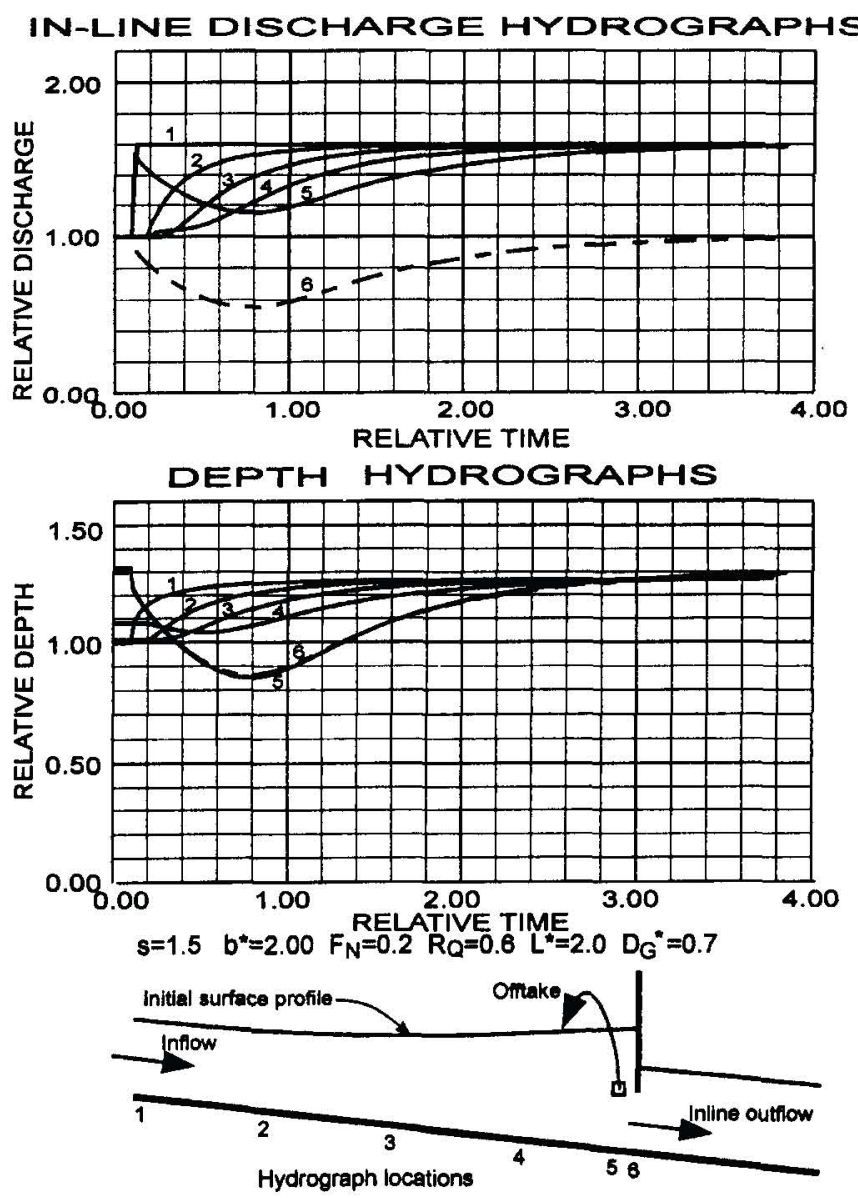

FIG. 8. Ideal Control-No Anticipation of Demand (Burt et al. 1995) 


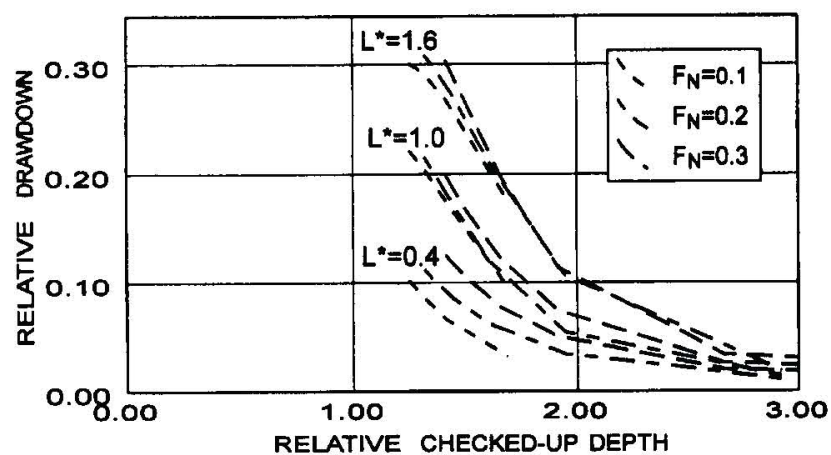

FIG. 9. Maximum Drawdown at Downstream Offtake under Ideal Control: $s=1.5 ; b^{*}=2.0 ; R_{Q}=0.6 ; F_{N}=0.1-0.3 ; L^{*}=0.4-1.6$ (Burt et al. 1995)

resent hydrograph locations: at the upstream end, at the quarter, half, and three-quarter points, and at pool end on either side of the offtake. Station 6, in the gate structure downstream from the offtake, is shown as a dot-dash. Noteworthy is the extreme length of time required to restore original conditions at the gate, as the necessary changes in pool volume are effected.

Fig. 9 is an example of generalized dimensionless graphs quantifying pool response in the chosen scenario. With relative drawdown defined as the maximum reduction in downstream depth divided by initial checked-up value, the curves show, for a $60 \%$ withdrawal fraction, the drawdown as a function of checked-up depth relative to normal depth, relative pool length, and initial Froude number. Complementary graphs would show the effects of different offtake ratios, relative bottom widths, and canal side slopes. From such curves, one can establish whether the drawdown is tolerable even with an exact, simultaneous replacement of discharge upstream, or whether anticipatory control is required.

\section{CONCLUSIONS}

The effect of canal hydraulic conditions on a steady backwater curve is small when expressed in nondimensional form. This suggests that this nondimensional form is useful for examining canal-pool properties in general.

It has been shown that pool properties have an important role to play in the response of pool levels and volumes to changes in flow, either known and anticipated or representing an unknown disturbance (e.g., unauthorized withdrawal, weed plug, etc.). Pool volume changes play an important role in controllability. These volume changes influence the speed of wave propagation, as demonstrated by differences in delay times stemming from different downstream control structures. Further, pool volume influences the water-level response to unanticipated downstream withdrawals.

The amount of backwater at the downstream end of a pool has a huge effect on its controllability. The writers therefore no longer recommend that irrigation canal pools be designed with normal depth at the downstream end under maximum flow conditions. Some additional backwater depth is necessary to allow sufficient control. Unfortunately, the technical analysis presented here may be insufficient to provide the necessary information for performing an economic analysis for the appropriate amount of backwater.

Our analyses suggest that not all flow changes in a canal pool can be accommodated by feedback alone. The amount of flow change that can be handled just by feedback is dependent upon the pool properties, the amount of allowable depth or pool volume change, and the properties of the feedback controller. This result emphasizes the need to include both feedback and feedforward components into canal control systems.

\section{APPENDIX I. REFERENCES}

Bautista, E., Clemmens, A. J., and Strelkoff, T. S. (1997). "Inverse computational methods for open-channel flow control." J. Irrig. and Drain. Engrg., ASCE, 123(2), 129-136.

Burt, C. M., Gooch, R. S., Strelkoff, T. S., and Deltour, J. L. (1995) "Response of ideally controlled canals to downstream withdrawals." Proc., 1st Int. Conf. on Water Resour. Engrg., ASCE, New York, N.Y., $169-173$

Burt, C. M., and Plusquellec, H. (1990). "Water delivery control," Management of farm irrigation systems, Hoffman, Howell, and Solomon, eds., American Society of Agric. Engrs., St. Joseph, Mich.

Clemmens, A. J., Kacerek, T., Grawitz, B. and Schuurmans, J. (1998). "Test cases for canal control algorithms." J. Irrig. and Drain. Engrg., ASCE, 124(1), 23-30.

Deltour, J. L. (1992). "Application de l'automatique numerique a la regulation des canaux," PhD Thesis, Institute de Mecanique de Grenoble, Grenoble, France.

Henderson, F. M. (1966). Open channel flow. Macmillan Company, New York, N.Y.

Malaterre, P.-O., Rogers, D. C., and Schuurmans, J. (1998). "Classification of canal control algorithms." J. Irrig. and Drain. Engrg., ASCE, 124(1), 3-10.

"Planning, operation, rehabilitation and automation of irrigation water delivery systems." (1987). Proc., Symp. by Irrig. and Drain. Div., D.D. Zimbelman, ed., ASCE, New York, N.Y.

Rogers, D. C., and Goussard, J. (1998). "Canal control algorithms currently in use." J. Irrig. and Drain. Engrg., ASCE, 124(1), 11-15.

Sanfilippo, F. (1994). "Application du PIR au cas des canaux a forte pente," Memoire, Université Claude Bernard, Lyon, France.

SIC user's guide and theoretical concepts. (1992). Cemagref.

Strelkoff, T. S. (1992). "Gradual development of bores in canal systems." Proc., Irrig. and Dran. Sessions at Water Forum '92, ASCE, Baltimore, Md., 456-461.

Strelkoff, T. S., and Clemmens, A. J. (1998). "Nondimensional expression of unsteady canal flow." J. Irrig. and Drain. Engrg., ASCE, $124(1), 59-62$

Strelkoff, T. S., Clemmens, A. J., and Gooch, R. S. (1995a). "Dimensionless characterization of canal pools." Proc., 1st Int. Conf. on Water Resour. Engrg., ASCE, New York, N.Y., 21-25.

Strelkoff, T. S., Deltour, J. L., and Baume, J. P. (1995b). "Propagation of upstream control measures along a canal pool." Proc., Ist Int. Conf. on Water Resour. Engrg., ASCE, New York, N.Y., 174-178.

Strelkoff, T. S., and Falvey, H. T. (1993). "Numerical methods used to model unsteady canal flow." J. Irrig. and Drain. Engrg., ASCE, $119(4), 637-655$

\section{APPENDIX II. NOTATION}

The following symbols are used in this paper:

$A=$ cross-sectional area $\left(L^{2}\right)$;

$A_{N}=$ cross-sectional area at normal depth in the characteristic flow $(L)$;

$a=$ ratio of average breadth to depth at normal depth for inflow, $Q_{N} ; Q_{R}=Q_{N} / a$

$B=$ top width (breadth);

$b=$ bottom width of trapezoidal section;

$D_{G}=$ gate opening:

$d_{N}=$ hydraulic depth (ratio of area to top width) at normal depth at the characteristic discharge;

$F_{N}=$ Froude number of characteristic discharge at normal depth in reference section;

$h=$ water-surface elevation $(L)$;

$L=$ reach length $(L)$

$N=$ subscript symbolizing conditions at normal depth in the characteristic flow, $Q_{N}$, in the reference section;

$n=$ Manning $n\left(L^{1 / 6}\right)$;

$n_{R}=$ Manning $n$ in reference section $\left(L^{1 / 6}\right)$;

$Q=$ discharge $\left(L^{3} / T\right)$;

$Q_{N}=$ normal (characteristic) discharge, for calculating $Y_{R}$ (see $a$ ) $\left(L^{3} / T\right)$;

$Q_{R}=$ reference discharge $\left(L^{3} / T\right)$ 
$q_{o}=$ distributed lateral outflow per unit length of channel $\left(L^{2} / T\right)$;

$R=$ hydraulic radius (cross-sectional area/wetted perimeter) $(L)$;

$R_{N}=$ hydraulic radius at normal depth in the characteristic flow $(L)$;

$R_{Q}=$ ratio of offtake withdrawal rate to initial flow, $Q_{N}$;

$S_{0}=$ bottom slope;

$S_{0_{R}}=$ bottom slope in a reference section;

$s$ = side slopes in a trapezoidal section;

$T_{R}=$ reference time $(T)$; $t=$ time $(T)$

$u_{o}=$ longitudinal component of velocity of lateral outflow ( $L /$ $T$ );

$V_{R}=$ reference velocity $(L / T)$;

$X_{R}=$ reference length for longitudinal dimensions $(L)$;

$x=$ distance along the channel $(L)$;

$Y_{R}=$ reference length for transverse dimensions $(L)$;

$y_{D}=$ checked-up depth, at downstream end of canal pool;

$y_{N}=$ normal depth at flow, $Q_{N}$ in reference section $(L)$; and

${ }^{*}=$ symbolizes a dimensionless variable. 